\title{
Asymmetric Transmission of Monetary Policy in Europe: a Markov-switching Approach
}

\author{
Torben W. Hendricks \\ University of Duisburg-Essen \\ Bernd Kempa \\ European University Viadrina
}

\begin{abstract}
This paper addresses the question of whether the common monetary policy of the European Central Bank is transmitted asymmetrically within the Euro area. To this end, we employ a Markov switching model to identify a credit channel of monetary policy transmission and investigate whether the credit channel is active or passive across four Euro-area countries (France, Germany, Italy and the Netherlands) as well as the United Kingdom at any given point in time. We find the timing and the duration of the regime switches into and out of the credit channel regime to be fairly synchronous for France, Germany and Italy, while being more heterogeneous for both the Netherlands and the United Kingdom. The asymmetry of the credit channel documented in this paper suggests that the heterogeneity of the monetary transmission mechanism is still very much present in the Euro area. This heterogeneity poses serious policy problems for the European Central Bank (ECB), as monetary policy continues to exert differential impacts across individual member countries of the monetary union. Also, it constitutes a convincing reason of why the $E C B$, the European Commission and a number of national governments actively push for further liberalization of financial markets in Europe.
\end{abstract}

\footnotetext{
*Corresponding address: Torben W. Hendricks: Department of Economics, University of DuisburgEssen, Universitaetsstr. 12, 45117 Essen, Germany, e-mail: torben.hendricks@uni-due.de. Corresponding author: Bernd Kempa: Department of Economics, University of Muenster, Universitaetsstr. 14-16, 48143 Muenster, Germany, Tel: +251 83 28660, Fax: +251 83 22826, e-mail: bernd.kempa@uni-muenster.de.
} 
- JEL Classification: C22, F36, F42

- Key Words: European monetary union, credit channel, Markov switching, monetary policy, asymmetric transmission

\section{Introduction}

The appropriateness of the "one-size-fits-all" monetary policy of the European Central Bank (ECB) has repeatedly been questioned in the academic literature. The stark differences in growth rates and the strong and persistent divergence of inflation rates across the member countries of the European Monetary Union (EMU) are only the most obvious manifestations of continuing fundamental asymmetries within the Euro area (Sinn and Reuter, 2001, Weber and Beck, 2005). The ECB is unable to address such asymmetries as the common monetary policy is geared towards the Euro area as a whole and not its individual member countries.

Apart from the fact that asymmetries may be a problem for the common monetary policy, the latter may itself be a source of heterogeneity in the Euro area. This argument rests on the presumption that the transmission of monetary policy works differently across the member countries of the union. In this context, Ganley and Salmon (1997), Hayo and Uhlenbrock (2000) and Dedola and Lippi (2005) have investigated the industry effects of monetary policy as a potential source of asymmetries. These authors detect strong heterogeneities in the cross-industry responses to monetary policy shocks, pointing to substantial differences in market structure in the European Union. Peersman and Smets (2005) estimate the differential effects of a Euro area-wide monetary policy change on output growth and also find considerable cross-industry heterogeneity. They trace the source of such heterogeneities to an interest rate and cost-of-capital channel, where the differences in the degree of asymmetry of policy effects are systematically related to differences in financial structure across the member countries of the Euro area. The interest rate pass-through and the strength of the cost channel is usually lower in bank-based financial systems such as those in continental Europe (Allen and Gale 2000, 2004), and more so in highly regulated banking systems such as Germany's, compared to somewhat less regulated systems such as France's or Italy's (Mojon, 2000). Chowdhury et al. (2006) confirm the heterogeneity of the 
cost channel for a number of countries including member countries of EMU, where the strength of the interest rate channel depends on the degree of regulation in financial markets. Focusing on the interest rate transmission across the largest EMU members, Clausen and Hayo (2006) find that the quantitative effects in Germany and Italy are fairly similar and both significantly larger than in France.

There is a strong presumption that credit markets play an important role in the monetary transmission process. In fact, a large and growing literature views the credit channel as the decisive conduit through which monetary policy affects the real economy. In this literature, the financial system is seen as both an accelerator of monetary impulses and as an independent source of non-monetary effects on the business cycle, with structural differences among the Euro-area countries usually regarded as the main source of transmission asymmetries (Kashyap and Stein, 1997, Dornbusch et al., 1998, De Bondt, 2000, Kakes, 2000, Chatelain et al., 2001, 2003, Sander and Kleimeier, 2004).

In this paper we present a novel approach of identifying the credit channel to analyze the asymmetric transmission of monetary policy in the Euro area. We are concerned with assessing the relative importance of the business cycle as well as other potential latent factors determining the effectiveness of the credit channel in individual EMU member countries over time. To this end, we employ a Markov switching model in which the parameters of the data generating process of the observed time series depend on an unobservable state variable which we associate with a genuine credit channel. The paper is structured as follows: Section II presents details on our estimation strategy, Section III reports on the estimation results, and a final section offers conclusions as well as some policy implications of our results.

\section{An Econometric Model for the Identification of the Credit Channel}

The textbook version of the monetary transmission mechanism usually considers only two assets, money and an interest-bearing paper such as a bond. Monetary policy may be effective if it impacts the interest rate on the bond as the sole relative price in such a model. This money view of the transmission process has long been challenged by the credit view associated with more elaborate multi-asset models. These models are characterized by imperfect substitutability among the various assets and a multitude of relative prices functioning as potential 
transmission mechanisms for monetary policy. ${ }^{1}$ As a special case of such a multiasset model, the lending view introduces bank loans as a distinct third asset beside money and bonds (Bernanke and Blinder, 1988). Monetary policy then impacts not only the interest rate on bonds but may work through an independent bank lending channel affecting the spread between loans and bonds or the quantity of bank loans available.

A more general definition of the credit view contemplates the whole range of financial intermediaries, identifying a broad credit channel with no special role for the banking sector (e.g. Bernanke, 1993, Bernanke et al., 1999, Carlstrom and Fuerst, 2001). The amplification effect of the broad credit channel comes through the role of the external finance premium which drives a wedge between the cost of internal and imperfectly collateralized external finance. This risk premium is due to informational asymmetries and can be regarded as compensation to lenders for the expected cost of monitoring, evaluation and contract enforcement. In models of the broad credit channel, the interest rate in period $t$ faced by firms, $R_{t}^{f}$, typically depends on the policy rate, $R_{t}$, and the external finance premium, $f_{t}$, which is increasing in the debt-to-equity ratio of the firm, $D_{t} / E_{t}$ (compare, e.g., Bean et al., 2002):

$$
R_{t}^{f}=R_{t}+f_{t}\left(\frac{D_{t}}{E_{t}}\right), f^{\prime}>0
$$

where small firms with weak balance sheets should be more strongly affected by changes in the cost of capital than large firms. Beside its direct effect, a rise in the policy rate has an indirect impact on the lending rate by affecting firms' debt-toequity ratio, as equity prices fall and firms' collateral deteriorates. This indirect effect is frequently referred to as the balance sheet channel.

Whereas the general existence of a broad credit channel appears to be rather uncontroversial, its intensity may vary over time in a nonlinear fashion. For example, Bernanke et al. (1999, p. 39) point out that "the dynamics of the [business] cycle are intrinsically nonlinear; more specifically, financial accelerator effects are stronger, the deeper the economy is in recession." In the same vein, DeBondt (2000, pp. 107-108) finds that "the relevance of the bank lending channel and particularly the balance sheet channel may be asymmetric over the business cycle", whereas Bean et al. (2002, p. 18) argue that "the credit channel can work in

\footnotetext{
${ }^{1}$ See Bernanke and Gertler (1995) for an overview and further references.
} 
a highly non-linear fashion, implying significant potential for asymmetries in monetary transmission."

In order to account for such nonlinearities, we allow for discrete shifts in the data generating process (DGP) by employing a Markov switching model (MSM). The Markov switching model, also referred to as regime switching model, was pioneered by Hamilton $(1989,1990)$, and has since developed into one of the most popular non-linear time series models. In this model, the nonlinearities are introduced via discrete shifts among any number of regimes. Here we allow for regime switching between two possible states, one state in which the credit channel is absent, denoted by $S_{t}=1$, and another in which it is operative, denoted by $S_{t}=2$. The model is estimated without any prior knowledge about possible break points, such that the identification of the two states is solely determined by the data.

In this class of nonlinear models the parameters of the DGP of the observed time series depend on an unobservable state variable which we associate with a genuine credit channel. In order to capture the amplification effect as the major characteristic of the credit channel, we measure the risk premium in financial markets by the average return differentials between mid-cap and large-cap stock price indices for various European countries. These return differentials can be viewed as a broad measure of the differential impact of monetary policy on the external finance premia across these classes of firms.

The model can be written as follows:

$$
\rho_{t}=c_{s_{t}}+X_{t} \beta_{s_{t}}+u_{t},
$$

where $\rho_{t}$ denotes the return differential in period $t, c_{s_{t}}$ is a (state-dependent) constant, $X_{t}$ is a matrix of conditioning information used to predict $\rho_{t}, \beta_{s_{t}}$ is the (state-dependent) vector of coefficients, and $u$ is the error term, with $u_{t} \sim$ $\operatorname{NID}\left(0, \sigma_{s_{t}}^{2}\right)$. Any regime shift between the two states represents a structural break in the data. If the timing of these shifts were known in advance, the approach would degenerate into a simple dummy variable model. However, as the states $S_{t}$ are not directly observable, we make the common assumption that these follow a first-order Markov chain. The underlying process can be described by the following transition probabilities governing the switches between the two states:

$$
\begin{aligned}
& \mathrm{p}_{11}=P\left(S_{t}=1 \mid S_{t-1}=1\right), \\
& \mathrm{p}_{12}=P\left(S_{t}=2 \mid S_{t-1}=1\right), \\
& \mathrm{p}_{21}=P\left(S_{t}=2 \mid S_{t-1}=2\right),
\end{aligned}
$$




$$
\mathrm{p}_{22}=P\left(S_{t}=1 \mid S_{t-1}=2\right),
$$

such that the probability of being in a particular state at time $t$ depends only on the state the system has been in at time $t-1 .^{2}$ The system may thus prevail in any of the two states for a random period of time, and is replaced by the other state when switching takes place. The attractive feature of this model is that no extraneous information is needed regarding the dates when the system was in each regime. The probability of the system being in a particular regime is solely inferred from the data. Suppose that the density conditional on being in state $j$, is Gaussian: ${ }^{3}$

$$
\eta\left(\rho_{t} \mid \Omega_{t-1}, S_{t}=j\right)=\frac{1}{\sqrt{2 \pi \sigma_{j}^{2}}} \exp \left(\frac{-\left(\rho_{t}-c_{j}-X_{t} \beta_{j}\right)^{2}}{2 \sigma_{j}^{2}}\right),
$$

for $j=1,2$, and $\Omega_{t-1}$ denoting information at time $t-1$. Then the log-likelihood function can be written as:

$$
l\left(\rho_{t} \mid \Omega_{t-1}\right)=\sum_{t=1}^{T} \operatorname{In}\left(\phi\left(\rho_{t} \mid \Omega_{t-1}\right)\right)
$$

where the density $\phi\left(\rho_{t} \mid \Omega_{t-1}\right)$ is the sum of the probability-weighted state densities, $\eta(\cdot)$, of the two states:

$$
\phi\left(\rho_{t} \mid \Omega_{t-1}\right)=\sum_{j=1}^{2} \eta\left(\rho_{t} \mid \Omega_{t-1}, S_{t}=j\right) P\left(S_{t}=j \mid \Omega_{t-1}\right) .
$$

Here $P\left(S_{t}=j \mid \Omega_{t-1}\right)$ denotes the conditional probability of being in state $j$ at time $t$ given information at time $t$ - 1 . The conditional state probabilities are obtained recursively:

$$
P\left(S_{t}=j \mid \Omega_{t-1}\right)=\sum_{k=1}^{2} P\left(S_{t}=j \mid S_{t-1}=k\right) P\left(S_{t-1}=k \mid \Omega_{t-1}\right),
$$

where $P\left(S_{t}=j \mid S_{t-1}=k\right)$ are the state transition probabilities of Eq. (3). Finally, the conditional state probabilities are updated according to Bayes' rule using the new information about the state of the economy, $S_{t}$, contained in the $t^{\text {th }}$ observation of the dependent variable, $\rho_{t}$ :

\footnotetext{
${ }^{2}$ The properties of Markov chains are discussed extensively in Hamilton (1994).

${ }^{3}$ This is not a particularly strong assumption since combinations of normals can accommodate densities with nonzero skewness and fat tails.
} 


$$
\begin{gathered}
P\left(S_{t}=j \mid \Omega_{t}\right)=P\left(S_{t}=j \mid \Omega_{t-1} ; \rho_{t}\right) \\
=\frac{\eta\left(\rho_{t} \mid S_{t}=j ; \Omega_{t-1}\right) P\left(S_{t}=j \mid \Omega_{t-1}\right)}{\sum_{j=1}^{2} \eta\left(\rho_{t} \mid S_{t}=j ; \Omega_{t-1}\right) P\left(S_{t}=j \mid \Omega_{t-1}\right)} .
\end{gathered}
$$

Eqs. (7) and (8) can be iterated on recursively to derive the state probabilities $P\left(S_{t}=j \mid \Omega_{t-1}\right)$ and to obtain the parameters of the likelihood function. There are various ways of estimating the Markov-switching model (see Hamilton, 1990, or Kim and Nelson, 1999). Here we use the Expectation Maximization (EM) algorithm discussed by Hamilton (1994) and Krolzig (1997), and drawing on the software provided by Hans-Martin Krolzig, to perform the iterations. ${ }^{4}$

\section{Empirical Evidence}

If a credit channel is operational, small firms with weak balance sheets should be more strongly affected by monetary policy impulses than are large firms. As a consequence, the cost-of-capital effects of monetary policy are likely to be more substantial for smaller and less well-capitalised firms relative to larger and bettercapitalised firms. One way of capturing such cost-of-capital effects would be to use some measure of the cost of external finance, for example in the form of commercial paper rates. As such data are currently unavailable on a disaggregated level for most EMU-area countries, we utilize the inverse of the price-earnings ratios of national mid-cap and large-cap stock price indices as an alternative measure of the external finance premia across these two classes of firms. The stock price indices used are the MDAX and DAX for Germany, the MidCAC and CAC for France, the FTSE Mid Cap and FTSE for Great Britain, and the AEX Mid Cap and AEX for the Netherlands. For Italy, disaggregated price-earnings ratios were only available for the small-cap segment, so we used these in relation to the priceearnings ratios of the aggregate Italian stock index. The Markov switching model is employed on the various national return differentials to investigate whether a credit channel of monetary policy transmission is active or passive at any point in time across four EMU countries (France, Germany, Italy and the Netherlands) as well as the United Kingdom. The model has the following specific format:

${ }^{4}$ Performing the iteration using data only up to period $t$ results in the filter probability, whereas utilizing the information in the whole data set yields the smoothed probability (Kim, 1994). 


$$
\rho_{t}=\left\{\begin{array}{ll}
c_{1}+a_{1}\left(S L B_{t}\right)+\beta_{1}\left(A I P_{t}\right)+\varepsilon_{1, t}, & S_{t}=1 \\
c_{2}+a_{2}\left(S L B_{t}\right)+\beta_{2}\left(A I P_{t}\right)+\varepsilon_{2, t}, & S_{t}=2
\end{array}\right\} .
$$

In (9) the return differential $\rho_{t}$ is regressed on the spread between 3-month and 10 -year government bond rates (short minus long bond, denoted $S L B$ ). Using an interest-rate spread rather than an individual short-term interest rate has the advantage of measuring more accurately the stance of monetary policy in the data. This can easily be illustrated by observing that in an environment of high interest rates, an elevated level of the short rate may not necessarily indicate a restrictive monetary policy. Moreover, such an interest rate spread is frequently used as an indicator of monetary policy because the long bond is relatively insensitive to short-run variations in monetary tightness or ease (Bernanke and Blinder, 1992).

The seasonally adjusted industrial production index constitutes the second independent variable in our model. In order to identify the impact of the business-

Table 1. Diagnostic Tests

\begin{tabular}{|c|c|c|c|c|c|}
\hline & $F R$ & $G E$ & $I T$ & $N L$ & $U K$ \\
\hline $\begin{array}{l}\text { Log-likelihood } \\
\text { MSM }\end{array}$ & -70.0796 & -38.6468 & -59.9822 & -78.9291 & -33.0108 \\
\hline $\begin{array}{l}\text { Log-likelihood } \\
\text { Linear system }\end{array}$ & -140.7541 & -96.6083 & -122.8761 & -104.6855 & -76.3814 \\
\hline LR-linearity-test & 141.3490 & 115.9230 & 125.7878 & 51.5128 & 86.7412 \\
\hline$\chi^{2}(6)$ & $* * *[0.0000]$ & $* * *[0.0000]$ & $* * *[0.0000]$ & $* * *[0.0000]$ & $* * *[0.0000]$ \\
\hline Normality-test & 0.5911 & 1.9262 & 0.2261 & 0.9304 & 2.0068 \\
\hline$\chi^{2}(2)$ & {$[0.7441]$} & {$[0.3817]$} & {$[0.8931]$} & {$[0.6280]$} & {$[0.3666]$} \\
\hline Hetero-test & 2.9590 & 1.3889 & 7.0424 & 7.7909 & 2.7565 \\
\hline$\chi^{2}(4)$ & {$[0.5647]$} & {$[0.8461]$} & [0.1337] & $*[0.0995]$ & {$[0.5994]$} \\
\hline Hetero-test & 0.6873 & 0.3140 & 1.7620 & 1.9772 & 0.6380 \\
\hline$\chi^{2}(4,53)$ & {$[0.6039]$} & {$[0.8674]$} & {$[0.1503]$} & {$[0.1114]$} & {$[0.6377]$} \\
\hline Hetero-X-test & 4.9110 & 1.4250 & 7.7158 & 7.7913 & 3.0283 \\
\hline$\chi^{2}(5)$ & {$[0.4268]$} & {$[0.9216]$} & {$[0.1726]$} & {$[0.1681]$} & {$[0.6956]$} \\
\hline Hetero-X-test & 0.9271 & 0.2530 & 1.5348 & 1.5520 & 0.5528 \\
\hline$\chi^{2}(5,52)$ & {$[0.4711]$} & {$[0.9364]$} & [0.1952] & {$[0.1901]$} & {$[0.7355]$} \\
\hline
\end{tabular}


Figure 1a. Residual Analysis for France

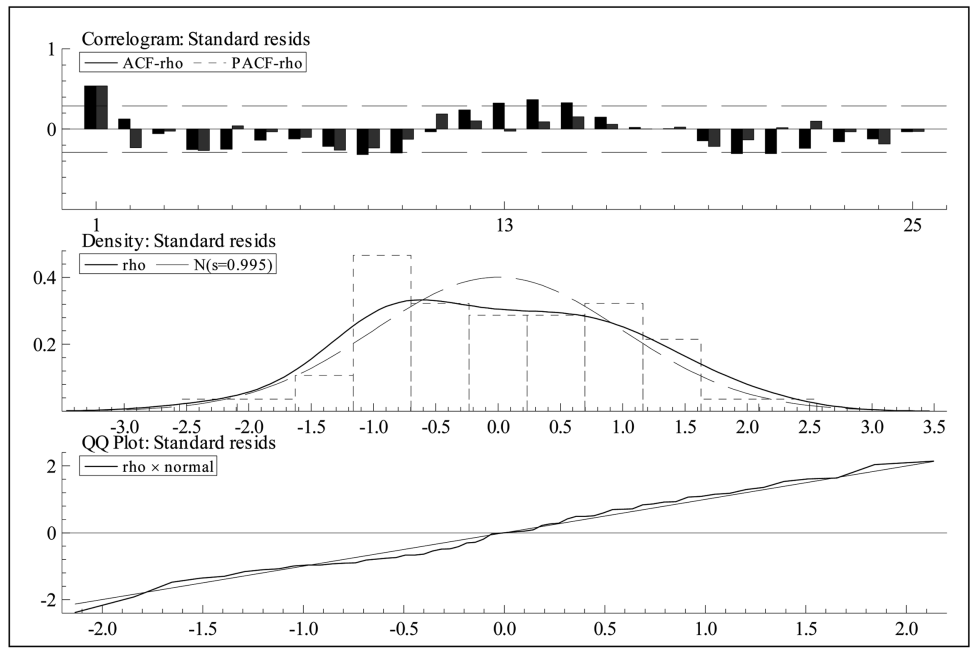

Figure 1b. Residual Analysis for Germany

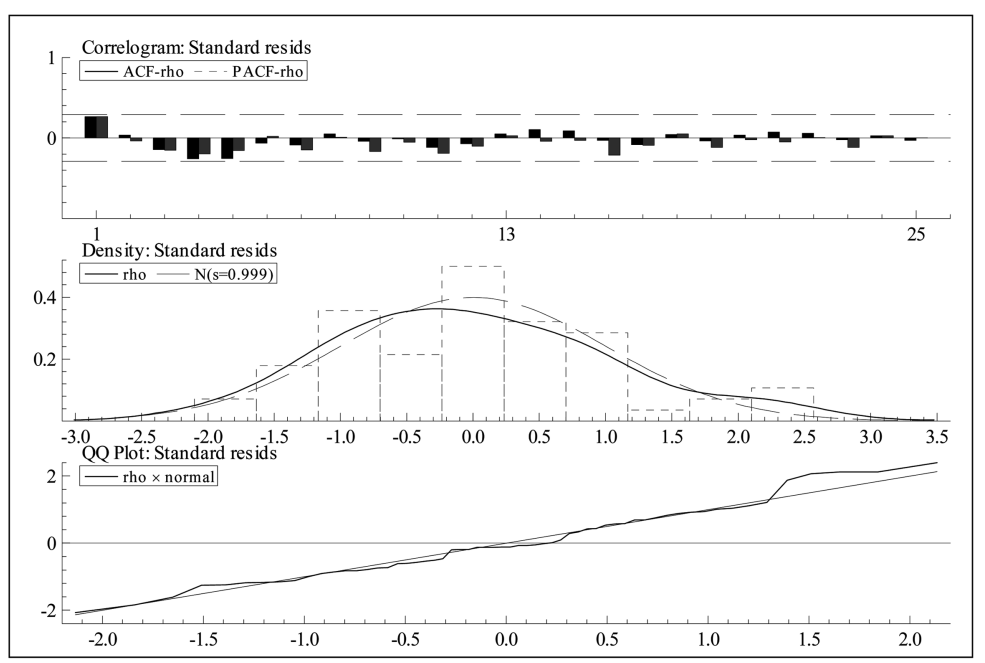

cycle component on the return differential, we include the annual rates of change of the index (annual industrial production, denoted $A I P$ ). Data are obtained from the IMF International Financial Statistics database, with the exception of the priceearnings ratios which are obtained from Thomson Financial Datastream. The sample consists of monthly data for the time period 2000(1)-2005(12).

The sample properties of the individual country data are summarized in Figure 1 
Figure 1c. Residual Analysis for Italy

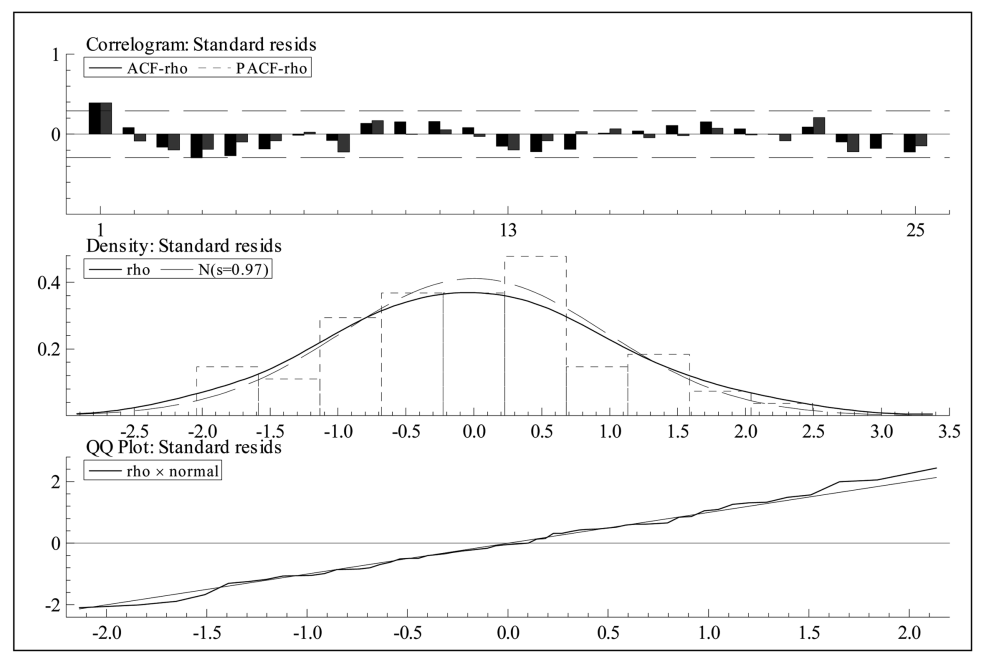

Figure 1d. Residual Analysis for Netherlands

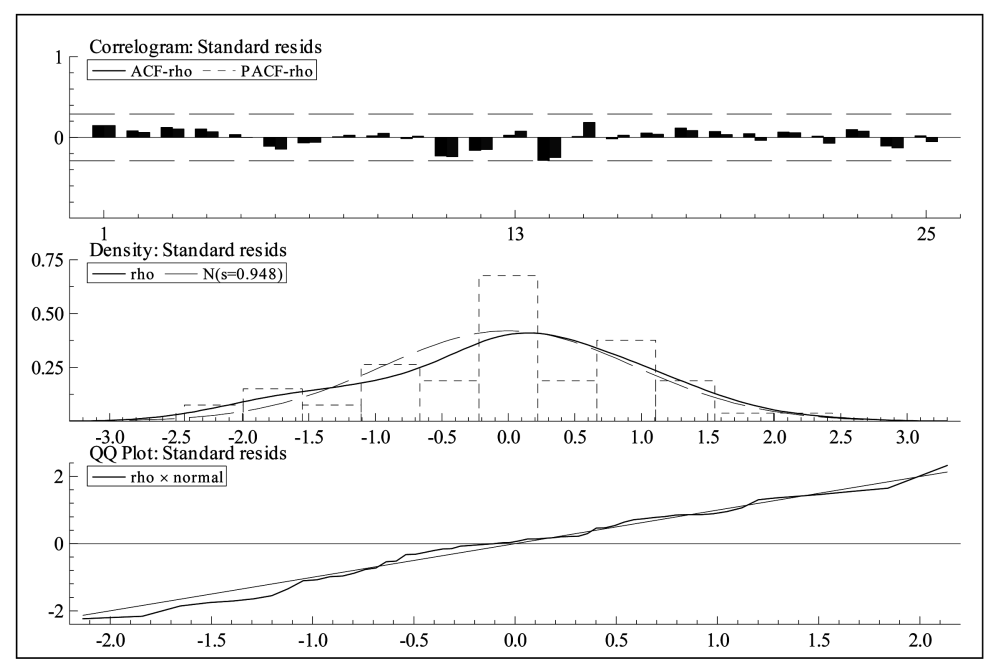

and Table 1. First of all, the appropriateness of the Markov switching model for the data at hand can be judged on the basis of the log-likelihoods and the likelihood ratio (LR) linearity tests reported in Table 1 . As the log-likelihoods of the Markovswitching model are significantly above the corresponding levels for the linear system for all countries, the Markov-switching model turns out to be the preferred estimation design relative to the linear alternative. This evidence is confirmed by the LR tests reported in the table. Davies $(1977,1987)$ has derived an upper bound 
Figure 1e. Residual Analysis for United Kingdom

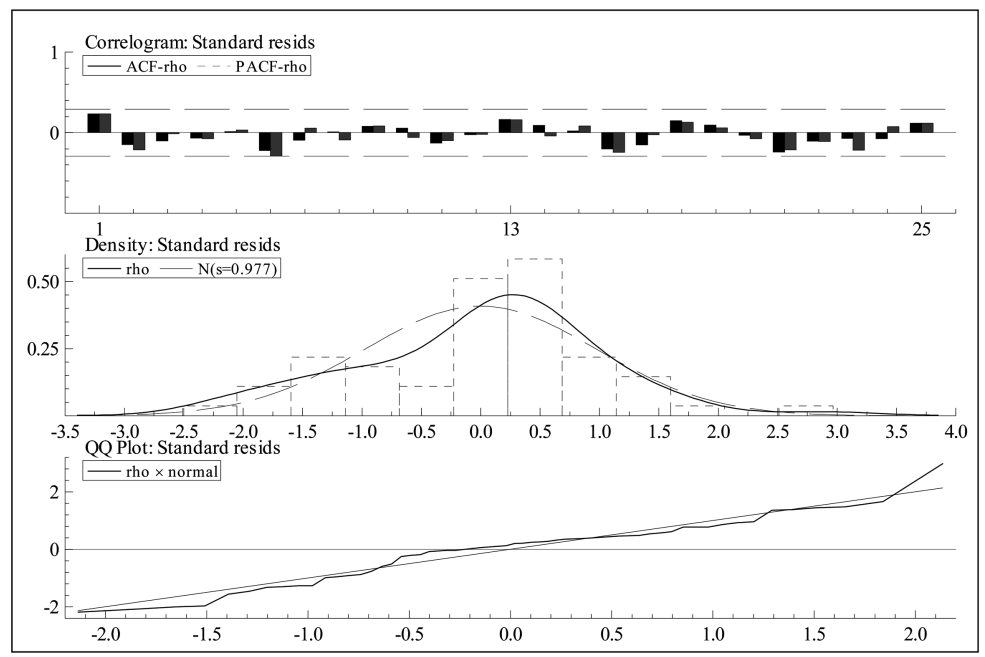

for the significance level of the LR test statistic under nuisance parameters. Formal tests of the Markov switching model against the linear alternative using a standardized likelihood ratio test designed to deliver asymptotically valid inference have been proposed by Hansen $(1992,1996)$ and Garcia (1998). However, as these tests are computationally demanding, we rely on the results of Ang and Bekaert (2002), which indicate that the critical values of the $\chi^{2}(r+n)$ distribution can be used to approximate the LR test, where $r$ is the number of restricted parameters and $n$ is the number of nuisance parameters.

Next, the correlograms of Figure 1 indicate no major problems with autocorrelated residuals. In order to account for the slight residual autocorrelation observed for France and Italy, confidence levels are computed on the basis of Newey-West HAC standard errors for these countries. Moreover, the density plots show the empirical densities to be well approximated by the normal distribution. This is confirmed both by the estimated quantile-quantile (QQ) plot of the residuals relative to the standard normal, as represented in the lower parts of Figure 1, and by the normality tests reported in Table 1 . We report the normality test due to Doornik and Hansen (1994) which tests whether the skewness and kurtosis of the residuals correspond to that of a normal distribution. This test gives appropriate rejection frequencies under the null of normality, using $\chi^{2}(2)$ critical values.

The tests for heteroscedasticity (hetero test and hetero-x test) follow White (1980), where in each case the null is unconditional homoscedasticity. The hetero 
test is based on an auxiliary regression of the squared residuals on the original explanatory variables and their squares, whereas the hetero-x test uses an analogous design, but adds the cross-products of the original regressors as arguments in the auxiliary regression. From these regressions we obtain the critical values as an LM statistic with $n R^{2} \sim \chi^{2}(k-1)$, with $k$ the sum of the number of restrictions plus the number of regressors including the constant. Alternatively, critical values can be obtained by means of an $F$-tests for the significance of $R^{2}$ based on $F(k-1, T-k)$, with $(T-k)$ as the degrees of freedom.

The results of the estimation are presented in Table 2. The two regimes identified by the Markov-switching model are denoted as Regime 1 and Regime 2. The two regimes are found to both be highly persistent, evidenced by transition probabilities close to unity of remaining in either Regime $1\left(p_{11}\right)$ or Regime $2\left(p_{22}\right)$. Correspondingly, the probabilities of regime switches from Regime 1 into Regime $2\left(p_{12}\right)$ and from Regime 2 into Regime $1\left(p_{21}\right)$ in any given month are close to zero for any of the sample countries.

In order to classify the two regimes with respect to the presence or absence of a credit channel, Table 2 reports the regression results for each of the two regimes identified by the Markov-switching model. It turns out that for all five countries of

Table 2a. Estimation Results for France

\begin{tabular}{lllll}
\hline & Coefficient & \multicolumn{2}{c}{ Standard error } & t-value \\
\hline Regime 1 & & & \\
constant & -6.0564 & $* * *$ & 0.3256 & -18.5989 \\
SLB & -2.3436 & $* * *$ & 0.2332 & -10.0483 \\
AIP & -0.0171 & & 0.0415 & -0.4121 \\
$\sigma_{I}$ & 0.3215 & & \\
$p_{11}$ & 0.9999 & & & \\
$p_{12}$ & 0.0001 & & & \\
\hline Regime 2 & & & 0.9065 & \\
constant & 3.4878 & $* * *$ & 0.5642 & 0.8516 \\
SLB & 0.4805 & & 0.1589 & -2.5683 \\
AIP & -0.4081 & $* *$ & & \\
$\sigma_{2}$ & 1.2735 & & & \\
$p_{21}$ & 0.9737 & & & \\
$p_{22}$ & 0.0263 & & & \\
\hline Astisks & & & \\
\hline
\end{tabular}

Asterisks refer to level of significance: $* 10 \%, * * 5 \%$, ***1\%, Newey-West HAC standard errors. 
the sample, the influence of monetary policy has a stronger impact on the default premium in Regime 2 compared to Regime 1. In particular, in Regime 2 an increase in the government bond spread (SLB) leads to a significant rise in the quality spread in all countries, except for France, where the effect has the expected sign but is insignificant. In contrast, in Regime 1 the effects of monetary policy are lower throughout. The evidence therefore suggests to identify Regime 2 as the situation in which the credit channel is active, and Regime 1 as the environment in which the credit channel is absent. This interpretation is confirmed by the effect of the business cycle variable (AIP) on the quality spread across the two regimes. In Regime 2, AIP has the expected sign and is significant for all countries with the exception of the Netherlands and the United Kingdom, where it is signed correctly but is insignificant. In contrast, the business cycle variable is insignificant for all countries in Regime 1 except for Germany and the Netherlands, where it is correctly signed and significant.

We can now turn to Figure 2 to identify for each country the relative likelihoods of being in either of the two regimes at any point in time. ${ }^{5}$ In each graph, the

Table 2b. Estimation Results for Germany

\begin{tabular}{lllll}
\hline & Coefficient & & Standard error & t-value \\
\hline Regime 1 & & & \\
constant & -0.3781 & & 0.3060 & -1.2358 \\
SLB & 0.3759 & $* *$ & 0.1702 & 2.2086 \\
$A I P$ & -0.2179 & $* * *$ & 0.0301 & -7.2451 \\
$\sigma_{1}$ & 0.3166 & & & \\
$p_{11}$ & 0.9999 & & & \\
$p_{12}$ & 0.0001 & & & \\
\hline Regime 2 & 3.6782 & $* * *$ & 0.4500 & \\
constant & 1.4454 & $* * *$ & 0.3106 & -3.6531 \\
SLB & -0.1386 & $* * *$ & 0.0409 & \\
AIP & 0.5783 & & & \\
$\sigma_{2}$ & 0.9666 & & & \\
$p_{21}$ & 0.0334 & & & \\
$p_{22}$ & & & \\
\hline Ast & & & \\
\hline
\end{tabular}

Asterisks refer to level of significance: $* 10 \%, * * 5 \%, * * * 1 \%$.

${ }^{5}$ Due to the use of annual growth rates in industrial production, the time series on the regime switches range from 2001(1) to 2005(12). 
Table 2c. Estimation Results for Italy

\begin{tabular}{lllll}
\hline & Coefficient & & Standard error & t-value \\
\hline Regime 1 & & & & \\
constant & -5.6587 & $* * *$ & 0.3914 & -14.4568 \\
SLB & -2.1326 & $* * *$ & 0.2313 & -9.2183 \\
AIP & 0.0636 & & 0.1006 & 0.6321 \\
$\sigma_{1}$ & 0.5459 & & & \\
$p_{11}$ & 0.9999 & & & \\
$p_{12}$ & 0.0001 & & & \\
\hline Regime 2 & & & 0.7768 & 3.4363 \\
constant & 2.6693 & $* * *$ & 0.4621 & 2.6170 \\
SLB & 1.2095 & $* *$ & 0.0582 & -10.4773 \\
AIP & -0.6098 & $* * *$ & & \\
$\sigma_{2}$ & 0.7626 & & & \\
$p_{21}$ & 0.9656 & & & \\
$p_{22}$ & 0.0344 & & & \\
\hline A & & & \\
\hline
\end{tabular}

Asterisks refer to level of significance: $* 10 \%, * * 5 \%, * * * 1 \%$, Newey-West HAC standard errors.

Table 2d. Estimation Results for the Netherlands

\begin{tabular}{|c|c|c|c|c|}
\hline & Coefficie & & Standard error & $t$-value \\
\hline \multicolumn{5}{|l|}{ Regime 1} \\
\hline constant & 0.4704 & & 0.8062 & 0.5835 \\
\hline$S L B$ & 0.1436 & & 0.4672 & 0.3073 \\
\hline$A I P$ & -0.3682 & $* * *$ & 0.0784 & -4.6956 \\
\hline$\sigma_{l}$ & 1.0184 & & & \\
\hline$p_{11}$ & 0.9664 & & & \\
\hline$p_{12}$ & 0.0336 & & & \\
\hline \multicolumn{5}{|l|}{ Regime 2} \\
\hline constant & -0.5762 & $*$ & 0.3413 & -1.6883 \\
\hline$S L B$ & 1.8984 & $* * *$ & 0.2589 & 7.3315 \\
\hline$A I P$ & -0.0837 & & 0.0709 & -1.1803 \\
\hline$\sigma_{2}$ & 0.5072 & & & \\
\hline$p_{21}$ & 0.9120 & & & \\
\hline$p_{22}$ & 0.0880 & & & \\
\hline
\end{tabular}

Asterisks refer to level of significance: $* 10 \%, * * 5 \%, * * * 1 \%$. 
Table 2e. Estimation Results for the United Kingdom

\begin{tabular}{|c|c|c|c|c|}
\hline & \multicolumn{2}{|c|}{ Coefficient } & Standard error & t-value \\
\hline \multicolumn{5}{|l|}{ Regime 1} \\
\hline constant & -1.3699 & $* * *$ & 0.0761 & -18.0040 \\
\hline$S L B$ & -0.4699 & $* * *$ & 0.0970 & -4.8464 \\
\hline$A I P$ & 0.0491 & & 0.0314 & 1.5621 \\
\hline$\sigma_{1}$ & 0.3336 & & & \\
\hline$p_{11}$ & 0.9450 & & & \\
\hline$p_{12}$ & 0.0550 & & & \\
\hline \multicolumn{5}{|l|}{ Regime 2} \\
\hline constant & 0.5441 & $* * *$ & 0.0884 & 6.1572 \\
\hline$S L B$ & 0.5973 & $* * *$ & 0.1108 & 5.3926 \\
\hline$A I P$ & -0.0488 & & 0.0465 & -1.0501 \\
\hline$\sigma_{2}$ & 0.3054 & & & \\
\hline$p_{21}$ & 0.8588 & & & \\
\hline$p_{22}$ & 0.1412 & & & \\
\hline
\end{tabular}

Asterisks refer to level of significance: $* 10 \%, * * 5 \%, * * * 1 \%$.

Figure 2a. Regime Probabilities: France

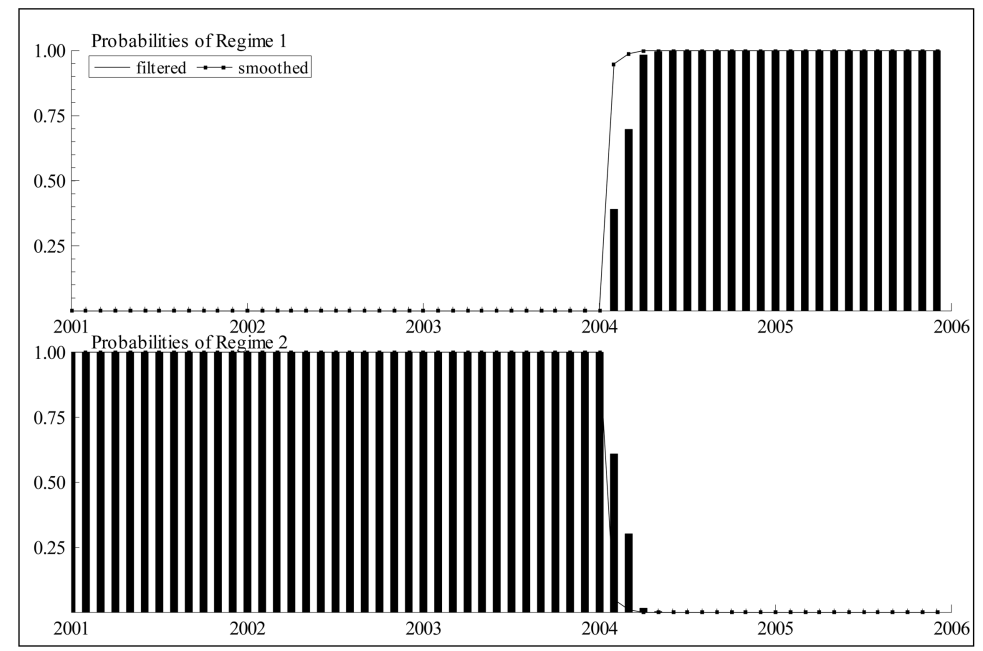


Figure 2b. Regime Probabilities: Germany

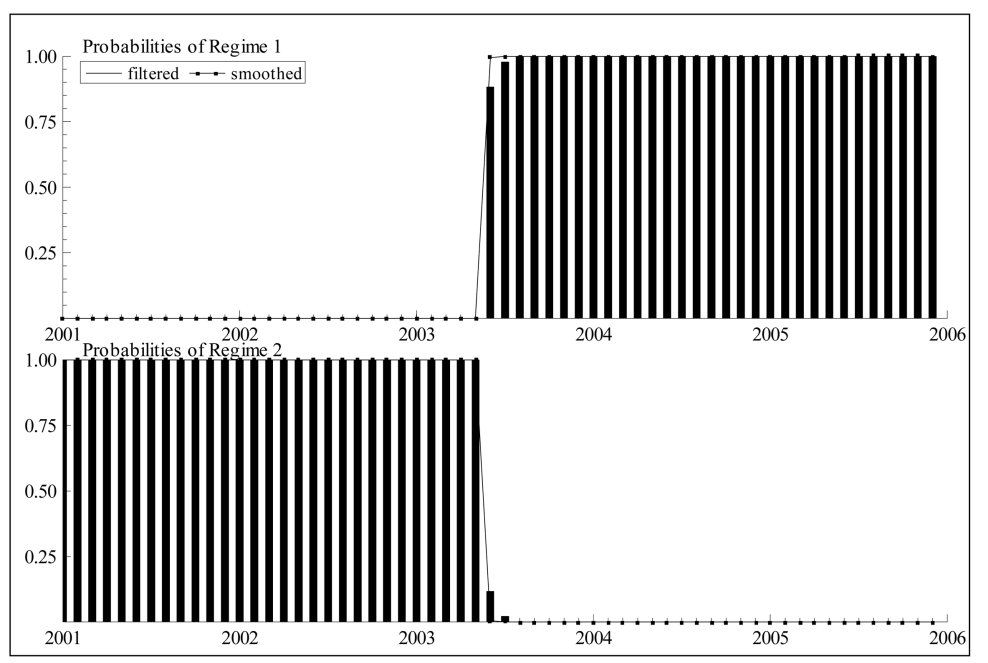

Figure 2c. Regime Probabilities: Italy

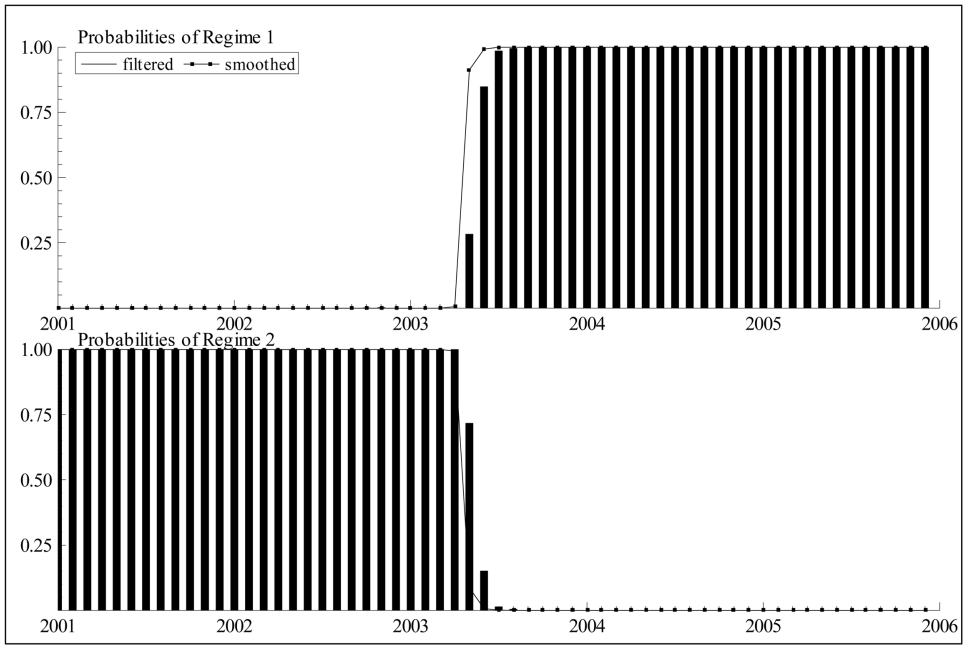

regime probabilities are specified separately for Regime 1 (upper panel) and Regime 2 (lower panel). The results show that the model identifies the individual regimes with a very high level of confidence as the probabilities mostly assume values close to 1.0. Due to the high persistence of the individual regimes, there are only few regime switches, ranging from a single switch each in France, Germany 
gure 2d. Regime Probabilities: Netherlands

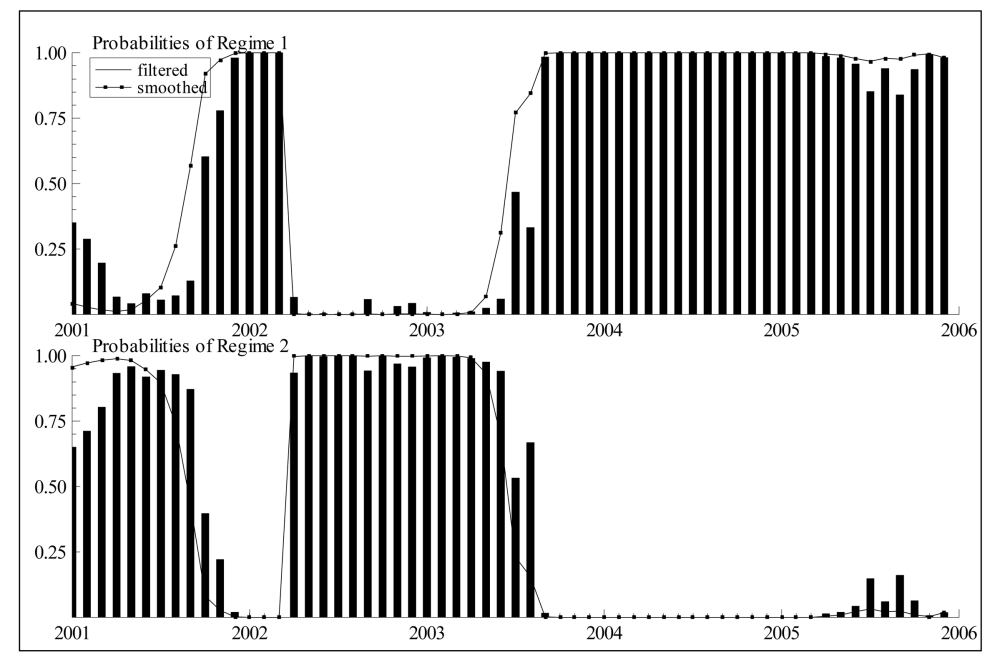

Figure 2e. Regime Probabilities: United Kingdom

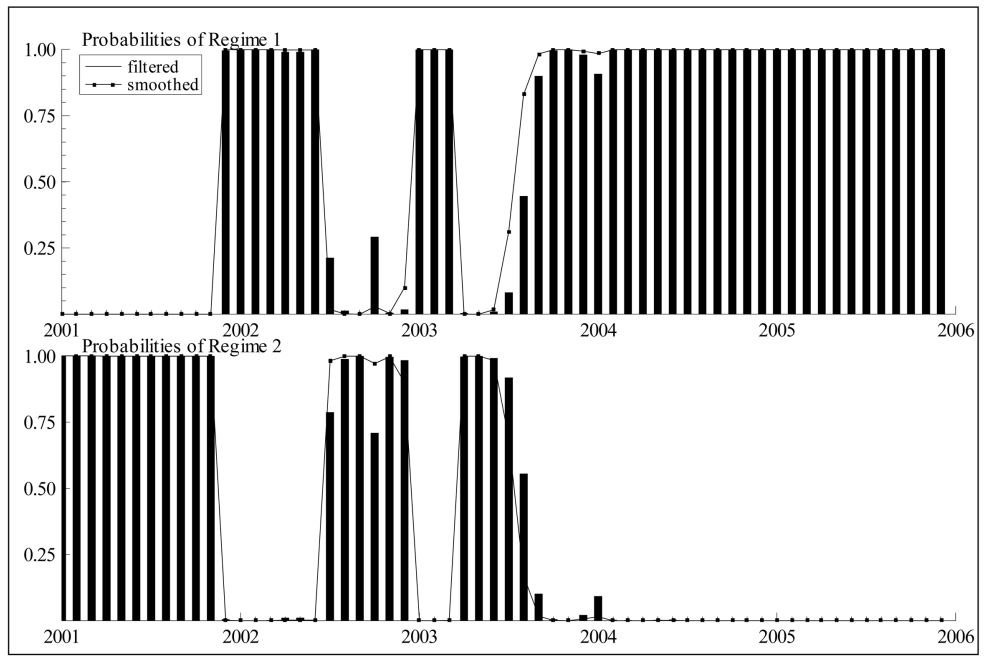

and Italy, to three in the Netherlands, and up to a total of five switches in the United Kingdom.

The systems start out in Regime 2 in which the credit channel is active in all countries. This observation can be motivated by the fact that at the start of the year 2001, financial markets were still in turmoil following the bursting of the New 
Table 3. Bilateral Credit Channel Correlations for Pairing of Countries

\begin{tabular}{llllll}
\hline & $F R$ & $G E$ & $I T$ & $N L$ & $U K$ \\
\hline$F R$ & 1.0000 & & & & \\
$G E$ & 0.7499 & 1.0000 & & & \\
$I T$ & 0.7252 & 0.9510 & 1.0000 & & \\
$N L$ & 0.6113 & 0.7341 & 0.6937 & 1.0000 & \\
$U K$ & 0.5689 & 0.6085 & 0.5648 & 0.6325 & 1.0000 \\
\hline
\end{tabular}

Economy bubble just a few months previously. Both the United Kingdom and the Netherlands switch into the passive Regime 1 later the same year before reverting back into the credit channel in the first half of the year 2002, most likely as a consequence of the insecurity in financial markets in the aftermath of the 9/11 terror attacks and the invasion of Afghanistan. The United Kingdom briefly switches back into the passive regime in early 2003, before reverting once more into the credit channel regime in the wake of the unfolding of the U.S. accounting scandals of 2002 and 2003. For the Euro-area countries these events apparently followed too quickly after each other to calm down financial markets enough to produce a regime switch, and all four countries stay in the active credit channel regime until 2003 (Germany, Italy and the Netherlands) or even 2004 (France). Thereafter, financial market jitters appear to subside and all countries reach the end of the sample staying in Regime 1 in which the credit channel is absent.

The time profiles of the regime switches reveal very different national dynamics of the credit channel associated with substantial heterogeneities in financial markets across the sample countries. From a visual inspection of the graphs, the switches into and out of the credit channel regime are fairly synchronous for France, Germany and Italy, but more heterogeneous for both the Netherlands and the United Kingdom. This impression is confirmed in Table 3, which reports on the contemporaneous bilateral correlation coefficients of the individual likelihoods of being in the credit channel regime for all possible pairings of countries. We find the highest correlations between Germany and Italy, somewhat lower coefficients for France and the Netherlands, and the lowest correlations for each of the individual EMU member countries relative to the United Kingdom. As the above discussion of the events surrounding the individual regime switches indicates, the low correlations for the United Kingdom can be traced to a much more rapid recuperation of the British financial markets from exogenous shocks. In this light, 
the high correlations within the Euro area should not be taken as sign of genuine financial integration, but rather as a manifestation of an entrenched inertia in the financial markets of these countries.

\section{Conclusion and Policy Implications}

The heterogeneity of financial structures within the Euro area constitutes a potential problem for the common monetary policy of the ECB. Our analysis has focused on the credit channel of monetary policy transmission as a major source of this heterogeneity. We argue that the effectiveness of transmitting monetary impulses into the real economy depends critically on the simultaneous presence or absence of a credit channel across all individual member countries of the Euro area. In this paper we have employed a Markov switching model to identify the credit channel of monetary policy transmission and to investigate whether the credit channel is active or passive across four Euro-area countries (France, Germany, Italy and the Netherlands) as well as the United Kingdom at any given point in time. We find the timing and the duration of the regime switches into and out of the credit channel regime to be fairly synchronous for France, Germany and Italy, while being more heterogeneous for both the Netherlands and the United Kingdom.

The results of our empirical analysis confirm the findings of earlier studies on monetary transmission in Europe. Using a different empirical methodology, DeBondt (2000) also finds the credit channel effects to be quite similar for France, Germany and Italy on the one hand relative to the Netherlands and the United Kingdom on the other hand. A number of recent studies relate these asymmetries in European financial markets to their depth, structure and regulation density (e.g. Allen and Gale, 2000, 2004, Peersman and Smets, 2005, Chowdhury et al., 2006).

Kashyap and Stein (1997) and Angeloni et al. (2003) point to the heterogeneity of the national banking industries across European countries. The banking systems in both the Netherlands and the United Kingdom are highly centralized with a number of large and well-capitalized banks. In contrast, the levels of concentration in the banking industries of France, Germany and Italy are comparatively low, banks are not particularly well capitalized, and relationship banking is commonplace. As a consequence, all three countries show significant loan supply effects that are related to the liquidity position of banks (compare Loupias et al., 2003, for France, Worms, 2003, for Germany, and Gambacorta, 2003, for Italy). 
Cecchetti (1999) associates the differences in financial structure to the heterogeneity of banking regulation across European countries. He finds that financial markets in the United Kingdom are the most flexible in Europe, closely followed by the Netherlands with only minor frictions. In contrast, France, Germany and Italy are all characterized by rather weak financial structures. In his view “...unless legal structures are harmonized across Europe, financial structures will remain diverse, and so will monetary transmission mechanisms" (Cecchetti, 1999, p. 22).

The asymmetry of the credit channel documented in this paper suggests that the heterogeneity of the monetary transmission mechanism is still very much present in the Euro area. This heterogeneity poses serious policy problems for the European Central Bank (ECB), as monetary policy continues to exert differential impacts across individual member countries of the monetary union. This policy dilemma may be one reason of why the ECB has used the interest rate instrument rather cautiously in the past. Also, it constitutes a convincing reason of why the ECB, the European Commission and a number of national governments actively push for further liberalization of financial markets in Europe.

A number of promising initiatives of financial liberalization are already underway in the Euro area. One project is the establishment of the Single Euro Payments Area (SEPA), which aims at making cashless cross-border payments as efficient and cheap as national payments, thus turning the fragmented national markets for cashless Euro payments into a single domestic market. A second program is the Markets in Financial Instruments Directive (MiFID), calling for the harmonization of the regulatory regime for investment services to increase competition and consumer protection in these markets. A third initiative is the Basel accords, particularly Basel II, which is concerned with the harmonization of banking laws and regulation, thus contributing to greater stability in the financial system. By fostering financial integration, these initiatives may be helpful in overcoming the fragmentation in European financial markets as well as imparting additional degrees of freedom on the monetary policy of the ECB.

Received 23 November 2007, Revised 22 January 2008, Accepted 01 February 2008 


\section{References}

Allen, F., Gale, D. (2000), Comparing Financial Systems, MIT Press, Cambridge, MA. Allen, F., Gale, D. (2004), Comparative Financial Systems: A Discussion, in: Bhattacharya, S., Boot, A., Thakor, A. (eds.), Credit, Intermediation, and the Macroeconomy, Oxford University Press, Oxford.

Ang, A., Bekaert, G. (2002), "Regime Switches in Interest Rates", Journal of Business and Economic Statistics, 20, 163-182.

Angeloni, I., Kashyap, A.K., Mojon, B., Terlizzese, D. (2003), "Monetary Transmission in the Euro Area: Does the Interest Rate Channel Explain All?", NBER Working Paper 9984.

Bean, C., Larsen, J., Nikolov, K. (2002), Financial Frictions and the Monetary Transmission Mechanism: Theory, Evidence and Policy Implications", ECB Working Paper No. 113.

Bernanke, B.S. (1993), "Credit and the Macroeconomy", Federal Reserve Bank of New York Quarterly Review, 18, 50-70.

Bernanke, B.S., Blinder, A.S. (1988), "Credit, Money, and Aggregate Demand", American Economic Review, Papers and Proceedings, 78, 435-439.

Bernanke, B.S., Blinder, A.S. (1992), "The Federal Funds Rate and the Channels of Monetary Transmission", American Economic Review, 82, 901-921.

Bernanke, B.S., Gertler, M. (1995), "Inside the Black Box: the Credit Channel of Monetary Policy Transmission”, Journal of Economic Perspectives, 9, 27-48.

Bernanke, B.S., Gertler, M., Gilchrist, S.G. (1999), “The Financial Accelerator in a Quantitative Business Cycle Framework”, in: Taylor, J.B., Woodford, M. (eds.), Handbook of Macroeconomics 1, North Holland, Amsterdam.

Carlstrom, C.T., Fuerst, T.S. (2001), "Monetary Shocks, Agency Costs, and Business Cycles", Carnegie-Rochester Conference Series on Public Policy, 54, 1-27.

Chatelain, J., Generale, A., Hernando, I., von Kalckreuth, U., Vermeulen, P. (2001), "New Findings on Firm Investment and Monetary Transmission in the Euro Area", Oxford Review of Economic Policy, 19, 73-83.

Chatelain, J., Ehrmann, M., Generale, A., Martínez-Pagés, J., Vermeulen, P., Worms, A. (2003), "Monetary Policy Transmission in the Euro Area: New Evidence from Micro Data on Firms and Banks", Journal of the European Economic Association, 1, 731742.

Cecchetti, S. (1999), "Legal Structure, Financial Structure and the Monetary Policy Transmission Mechanism", Federal Reserve Bank of New York Economic Policy Review, 5, 9-28.

Chowdhury, I., Hoffmann, M., Schabert, A. (2006), "Inflation Dynamics and the Cost Channel of Monetary Transmission”, European Economic Review, 50, 995-1016.

Clausen, V., Hayo, B. (2006), “Asymmetric Monetary Policy Effects in EMU”, Applied Economics, 38, 1123-1134. 
Davies, R.B. (1977), "Hypothesis Testing when a Nuisance Parameter is Present only under the Alternative, Biometrika, 64, 247-254.

Davies, R.B. (1987), "Hypothesis Testing when a Nuisance Parameter is Present only under the Alternative", Biometrika, 74, 33-43.

De Bondt, G.J. (2000), "Financial Structure and Monetary Transmission in Europe", Edward Elgar, Cheltenham, UK.

Dedola, L., Lippi, F. (2005), “The Monetary Transmission Mechanism: Evidence from the Industries of Five OECD Countries", European Economic Review, 49, 1543-1569.

Doornik, J., Hansen, H. (1994), "A Practical Test for Univariate and Multivariate Normality", Discussion paper, Nuffield College.

Dornbusch, R., Favero, C., Giavazzi, F. (1998), "Immediate Challenges for the ECB issues in Formulating a Single Monetary Policy", Economic Policy, 14, 17-52.

Gambacorta, L. (2003), "The Italian Banking System and Monetary Policy Transmission: Evidence from Bank-level Data", in: Angeloni, I., Kashyap, A., Mojon, B. (eds.), Monetary Transmission in the Euro Area, Cambridge University Press, Chapter 19.

Ganley, J., Salmon, C.(1997), "The Industrial Impact of Monetary Policy Shocks: Some Stylised Facts", Bank of England Working Paper No. 68.

Garcia, R. (1998), "Asymptotic Null Distribution of the Likelihood Ratio Test in Markov Switching Models", International Economic Review, 39, 763-788.

Hamilton, J. (1989), "A New Approach to the Economic Analysis of Non-stationary Time Series and the Business Cycle", Econometrica, 57, 357-384.

Hamilton, J. (1990), "Analysis of Time Series Subject to Changes in Regime”, Journal of Econometrics, 45, 39-70.

Hamilton, J. (1994), Time Series Analysis, Princeton University Press, Princeton, NJ.

Hansen, B.E. (1992), "The Likelihood Ratio Test under Non-standard Conditions: Testing the Markov Switching Model of GNP”, Journal of Applied Econometrics, 7, S61S82.

Hansen, B.E. (1996), "Erratum: The Likelihood Ratio Test under Non-standard Conditions: Testing the Markov Switching Model of GNP", Journal of Applied Econometrics, 11, 195-199.

Hayo, B., Uhlenbrock, B. (2000), "Industry Effects of Monetary Policy in Germany”, in: Von Hagen, J., Waller, C.J., Regional Aspects of Monetary Policy in Europe, Kluwer, Boston.

Kakes, J. (2000), "Monetary Transmission in Europe: The Role of Financial Markets and Credit", Edward Elgar, Cheltenham, UK.

Kashyap, A.K., Stein, J.C. (1997), "The Role of Banks in Monetary Policy: A Survey with Implications for the European Monetary Union", Federal Reserve Bank of Chicago Economic Perspectives, 21, No. 5, 2-18.

Kim, C. (1994), "Dynamic Linear Models with Markov-switching", Journal of Econometrics, 60, 1-22.

Kim, C., Nelson, C.R. (1999), "State-Space Models with Regime-Switching: Classical and Gibbs-Sampling Approaches with Applications", MIT Press, Cambridge, MA. 
Krolzig, H.M. (1997), Markov Switching Autoregressions, Springer Verlag, Berlin.

Loupias, C., Savignac, F., Sevestre, P. (2003), "Is There a Bank-lending Channel in France? Evidence from Bank Panel Data", in: Angeloni, I., Kashyap, A., Mojon, B. (eds.) Monetary Transmission in the Euro Area, Cambridge University Press, Chapter 17.

Mojon, B. (2000), "Financial structure and the Interest Rate Channel of the ECB Monetary Policy", ECB Working Paper No. 40.

Peersman, G., Smets, F. (2005), "The Industry Effects of Monetary Policy in the Euro Area", Economic Journal, 115, 319-342.

Sander, H., Kleimeier, S. (2004), "Convergence in Euro-zone Retail Banking? What Interest Rate Pass-through Tells Us about Monetary Policy Transmission, Competition and Integration", Journal of International Money and Finance, 23, 461492.

Sinn, H., Reutter, M. (2001), “The Minimum Inflation Rate for Euroland”, NBER Working Paper 8085.

Weber, A.A., Beck, G.W. (2005), "Price Stability, Inflation Convergence and Diversity in EMU: Does One Size Fit All?’, Manuscript, Frankfurt University.

White, H.L. (1980), "A Heteroskedastic-consistent Covariance Matrix Estimator and a Direct Test for Heteroskedasticity", Econometrica, 48, 817-838.

Worms, A. (2003), "The Reaction of Bank-lending to Monetary Policy Measures in Germany", in: Angeloni, I., Kashyap, A., Mojon, B. (eds.) Monetary Transmission in the Euro Area, Cambridge University Press, Chapter 15. 